IZA DP No. 6388

Experimental Evidence of Self-Image Concerns as Motivation for Giving

Mirco Tonin

Michael Vlassopoulos

February 2012 


\title{
Experimental Evidence of Self-Image Concerns as Motivation for Giving
}

\author{
Mirco Tonin \\ University of Southampton, \\ Central European University and IZA \\ Michael Vlassopoulos \\ University of Southampton
}

Discussion Paper No. 6388

February 2012

IZA
P.O. Box 7240
53072 Bonn
Germany

Phone: +49-228-3894-0

Fax: +49-228-3894-180

E-mail: iza@iza.org

\begin{abstract}
Any opinions expressed here are those of the author(s) and not those of IZA. Research published in this series may include views on policy, but the institute itself takes no institutional policy positions.

The Institute for the Study of Labor (IZA) in Bonn is a local and virtual international research center and a place of communication between science, politics and business. IZA is an independent nonprofit organization supported by Deutsche Post Foundation. The center is associated with the University of Bonn and offers a stimulating research environment through its international network, workshops and conferences, data service, project support, research visits and doctoral program. IZA engages in (i) original and internationally competitive research in all fields of labor economics, (ii) development of policy concepts, and (iii) dissemination of research results and concepts to the interested public.
\end{abstract}

IZA Discussion Papers often represent preliminary work and are circulated to encourage discussion. Citation of such a paper should account for its provisional character. A revised version may be available directly from the author. 
IZA Discussion Paper No. 6388

February 2012

\section{ABSTRACT}

\section{Experimental Evidence of Self-Image Concerns as Motivation for Giving}

We conduct an experiment in which subjects make a series of decisions of allocating an endowment of $£ 10$ between themselves and a passive recipient that is either a charity or the experimenter. When making these decisions subjects are informed that one of them will be chosen randomly at the end to determine payoffs. After all decisions have been made and it has been revealed which decision will determine payoffs we offer subjects an opportunity to opt out from their initial decision and receive $£ 10$ instead. We find that around one third of subjects choose to opt out. The fact that a subject decides to revise a decision to give and chooses instead to exit and keep the whole amount - an option that was available when she made the first decision and was not exercised - indicates that giving in the first instance was not motivated solely by altruism toward the recipient. We argue that opting out indicates that giving is also motivated by self-image concerns.

JEL Classification: C91, D03, D64

Keywords: dictator game, charitable giving, opting-out, self-image

Corresponding author:

Mirco Tonin

School of Social Sciences

University of Southampton

Southampton SO17 1BJ

United Kingdom

E-mail:m.tonin@soton.ac.uk

\footnotetext{
* This work was supported by the Economic and Social Research Council [grant number RES-061-250461] and by the British Academy through a Small Research Grant.
} 


\section{Introduction}

This paper provides evidence of self-image concerns as motivation behind charitable giving. Psychologists have long recognized that maintenance of a perception of one's self as a kind and helpful person is an important determinant of prosocial behavior. The main idea is that people draw inferences about their prosocial disposition from their actions (Baumeister, 1998; Bem, 1972); for instance, when a charity solicits a donation then making a contribution signals to the donor positive personality traits. More recently, self-image has also been identified as an important motivator of prosocial behavior in the economics literature (Benabou and Tirole, 2006; Bodner and Prelec, 2003; Grossman, 2010; Murnighan et al., 2001). We contribute to this strand of the literature by providing empirical support for the importance of self-image considerations in the context of a modified dictator game.

In particular, subjects in our experiment made a series of decisions of allocating an endowment of $£ 10$ between themselves and a passive recipient that was either a charity or the experimenter. When making these decisions subjects were informed that one of them would be chosen randomly at the end to determine payoffs. When all decisions were made and it was revealed which decision would determine payoffs we offered subjects an opportunity to exit the game and receive the $£ 10$ instead. This option was not pre-announced so subjects were unaware of the possibility of revision when making the allocation decisions. We found that around one third of those who had given something in the decision that was implemented chose to opt out.

The fact that a subject decides to revise a decision to give and chooses instead to exit and keep the whole amount - an option that was available when she made the first decision and was not exercised - indicates that giving in the first instance was not motivated solely by concerns about final payoffs but also by audience effects. The role that audience effects play in shaping prosocial behavior and how they interact with monetary incentives has recently received considerable attention both theoretically (Benabou and Tirole, 2006; Ellingsen and Johannesson, 2008, 2011; Andreoni and Bernheim, 2009), and empirically in the lab and the field (Ariely et al., 2009; Grossman, 2010; Lacetera and Macis, 2010; DellaVigna et al., 2011). Since in our experiment decisions are anonymous, and in two of the decisions the recipient is a charity who will remain unaware of the donor's identity or of the fact that there was an experiment being conducted, leaves us with the only candidate audience being the person herself. ${ }^{1}$ How does a concern for self-image explain exiting behavior in our setting? There are two possible mechanisms through which this could take place. First, recall that subjects in our experiment were offered three chances to prove

\footnotetext{
${ }^{1}$ In principle, it is possible that subjects may be concerned about how the experimenter will judge their decision, however, this concern should be muted here as the experimenter cannot link decisions to specific subjects. Moreover, if subjects are concerned with the experimenters' judgement of their decision, we would expect less opting out when the experimenters are the recipients. Instead, as we will show in section 3 , the opposite is true.
} 
to themselves that they are altruistic before being given the option to opt out. A subject that, for instance, shared an amount with the recipient during the course of the experiment has upheld the self-image of being a caring type. Now, when given the opportunity to opt out, some subjects may feel that they have already signaled their generosity in their earlier donation decisions, even if these decisions were not executed, and may therefore decide to opt out and receive the full 110 . The point is that getting $£ 10$ by opting out of a previous donation is different from keeping $£ 10$ for oneself in the original allocation decision, because in the former case the subject has shown herself her good intentions, while in the latter this is not the case. An additional mechanism explaining opting out is that when deciding how to share the $£ 10$, the subject faced the monetary cost of this decision only with a probability of one third. On the other hand, the benefit of self-signaling may be experienced regardless of implementation. At the opting out stage, the monetary costs of adhering to the previous decision are certain, as opting out applies to the specific decision that has been selected for implementation. This increase in costs can tilt the cost-benefit analysis for some subjects in the direction of opting out. All in all, opting out can be explained through a combination of a reduced benefit of self-signaling due to satiation and an increase in its costs due to the removal of the uncertainty surrounding implementation.

Our experimental design draws on a recent literature that studies exiting behavior in dictator games. This literature was launched with the paper by Dana et al. (2006) who gave dictators the opportunity for a costly exit and found that about a third of the subjects were willing to sacrifice a dollar in order that the recipient never finds out that a dictator game was played. By contrast, in a slight variation of this experiment in which the recipients would never find out that a dictator game was played the authors found that almost none of the dictators exercised the option to exit. Broberg et al. (2007) followed up on the study by Dana et al. (2006) by estimating the distribution of exit reservation prices in a dictator game and found that the mean exiting reservation price to be about $80 \%$ of the dictator's endowment. These results indicate that standard models of social preferences where dictators care about the payoff of recipients or dislike unfair outcomes (e.g. Fehr and Schmidt, 1999) cannot fully explain giving in the dictator game. Instead, dictators may have some concern about not meeting the expectation of the recipient and, therefore, if they can avoid having to let someone down they would do it even at a cost. Notice, however, that this interpretation of exiting behavior is open to debate in light of the evidence in Ellingsen et al. (2010) who find no correlation between dictators' giving and the beliefs of the recipients about how much they would receive, when those beliefs had been communicated to the dictator before the decision was made. Differently from the above studies in which the exiting option is presented to subjects after they have made the sharing decision, Lazear et al. (2012) perform experiments in which subjects are offered the option of either playing the dictator game or receiving a fixed payment and subjectrecipients remaining ignorant of the sharing possibility. They found that more than half of subjects 
take the exit option. ${ }^{2}$ In our experimental design aversion to disappointing dictator recipients cannot explain opting out behavior, as either the recipient is never aware (charity) or is always aware (experimenter) of the game being played. This feature of our design differentiates it from previous studies where the choice to exit has implications for the recipient's awareness. Moreover, the fact that the choice to opt out concerns a sharing decision that has already been taken makes it implausible that exiting is explained by a desire to avoid being in a sharing environment, an explanation for exiting that has been proposed in the papers where opting out takes place before the actual sharing decision. We claim that exiting behavior in our setting is consistent with giving motivated by self-image concerns

The structure of the rest of the paper is as follows: the next section describes the procedures, experimental design, and sample selection, while section 3 presents the results. The last section offers a discussion and some concluding remarks.

\section{The Experiment}

\subsection{Procedures}

We conducted 13 experimental sessions in the fall of 2009 at the University of Southampton, involving a total of 251 students of diverse academic backgrounds, with the exclusion of economics and psychology. We invited an equal number of male and female subjects in each session. The number of participants in each session ranged between 15 and 25. We ran the sessions in large classrooms and asked subjects to take isolated seats in order to guarantee their privacy. At the beginning of the experiment, we read aloud an information sheet with some general instructions regarding the experiment (see Appendix). We then collected the participation consent forms and distributed envelopes containing a $£ 5$ show up fee and a 5-digit personal code number. Subjects would use this number to identify their decisions throughout the experiment and to collect their earnings at the end, thus ensuring their anonymity. We then informed participants that they will receive sequentially three decision sheets (A, B, and $\mathrm{C}$ ), where they will be asked to decide how to allocate $£ 10$. We also informed them that after all decisions are made, one of the three decision sheets will be randomly selected for implementation, and explained in detail the selection procedure. $^{3}$ Notice that the selection procedure is such that in expectation each of the three

\footnotetext{
${ }^{2}$ Jacobsen et al. (2011) also find substantial exiting in a setting where subjects are offered an opportunity to avoid having to share their endowment with a charity and are informed about this option ex-ante.

${ }^{3}$ Immediately after the distribution of the envelopes with the personal code number, we randomly selected in each session a monitor to verify that the experimenters followed the protocol. The monitor was also responsible for the selection procedure. In particular, after all three decisions were made the monitor drew from an envelope containing cards with the numbers 1,2 and 3 printed on them. The code number of each participant ended in either 1,2 or 3. Decision A (B) [C] was implemented for participants having a code number ending in the first (second) [third]
} 
decisions is implemented for one-third of participants in a given session. ${ }^{4}$

We then distributed to participants the instructions and decision sheet for each decision sequentially. After the three allocation decisions had been made and after selecting one of them for implementation, participants were informed that before carrying out the payment they had an opportunity to opt out. This implied that the decision randomly selected among the three would not be implemented and they would instead receive $£ 10$ at the end of the session. In particular, at this stage we told participants:

"You have just made three decisions on how to allocate $£ 10$ and one of these has been randomly selected to be implemented. Before carrying out the payment associated with your choice you are given an opportunity to opt out. This will imply that the decision you made will not be implemented and you will instead receive $£ 10$ at the end of the session. If you decide not to opt out then you will receive the payment associated with the decision that was previously selected."

Note that subjects were not aware of this option when taking the three decisions on how to allocate £10. At the end, participants completed a short questionnaire while we arranged the payments. A session lasted approximately one hour.

\subsection{Treatments}

In the three sequential decisions labelled as DA, DB, and DC, we asked participants to decide how to allocate $£ 10$ between themselves and a recipient in three different conditions in which we either vary the recipient (experimenter, charity) or amount received by the recipient (fixed, varying). In particular, in one condition that we will label $\mathrm{T} 1$, the experimenters were the recipient and the amount received corresponded to the one passed by the participant. The other two conditions involved a charity that the participant could in each case choose from a list of ten. ${ }^{5}$ In the condition that we label T2, the amount that the charity would receive was fixed at £10, regardless of the experimental subject's choice, ${ }^{6}$ while in condition T3, the amount received by the charity was given by the subject's allocation. Subjects underwent the three conditions in a randomized order, with 5 out of 6 unique orders implemented twice and one implemented three times. Consequently, in some sessions the first decision faced by participants, decision A or DA, corresponded to T1, in others

number the monitor drew.

${ }^{4}$ In the questionnaire at the end of the experiment, subjects indicated that they understood well this random implementation. In particular, the question was "when I took my decisions I understood that only one would be implemented", with possible answers ranging between 1 (Strongly Disagree) and 5 (Strongly Agree). The average response for the sample that is used in the paper is 4.7 .

${ }^{5}$ Among the ten charities, the most selected one is Cancer Research UK, followed by Doctors without Borders and National Society for the Prevention of Cruelty to Children.

${ }^{6}$ In particular, in this treatment we informed subject that "the experimenters will pay your selected charity a top-up (the difference between $£ 10$ and what you choose to pass) so that in total the charity receives $£ 10 "$ and that "in total your selected charity will receive neither more nor less than $£ 10 "$. 
to T2, in others to T3. The same for the second decision, DB, and the third, DC. These decisions have been analyzed in a companion paper (Tonin and Vlassopoulos, 2011) aimed at distinguishing and quantifying the two types of intrinsic motivation for giving that have been underlined in the literature: pure altruism and warm glow (Andreoni, 1989, 1990). The focus of this paper is instead on the opt-out decision that takes place after the selection of which of the three decisions on how to allocate $£ 10$ to implement.

\subsection{Sample}

As mentioned earlier, a total of 251 subjects participated in the experiment. Of these, 13 participants acted as monitors, leaving 238 subjects who made decisions. To check for understanding of the instructions, we asked participants to respond to questions about hypothetical allocation decisions before making each of the three sequential decisions. 133 answered all questions testing understanding of the treatments correctly, while most mistakes occurred in T2. However, out of 98 subjects making a mistake in T2, 63 provided the correct answers regarding the amounts the charity and the subject receive, while making a mistake regarding the experimenter contribution to the charity. Considering that all these subjects understood the essential parts of T2, we conduct the analysis including them. At the end, we have a sample of 192 subjects ( $81 \%$ of the original sample) who answered correctly to questions regarding T1 and T3 and at least answered correctly the questions about the amounts received by the charity and the subject for T2. We have also conducted the analysis using the smaller sample of 133 subjects who answered all questions correctly and the whole sample of 238 participants. The results (available upon request) are very similar. The average donation decision among the 192 participants in our sample was $£ 1.77$ for T1 (with $55 \%$ giving 0), £1.84 for T2 (with $57 \%$ giving 0 ) and $£ 4.29$ for T3 (with $19 \%$ giving 0 ).

\section{Results}

Almost a quarter of our sample (46 out of 192) decided to opt out. Notice, however, that subjects for whom the selected decision implied a $£ 10$ payment to themselves, opting out or not has no implications whatsoever in terms of the payment they receive at the end of the experiment. For instance, if I decided to pass nothing to charities in T3 and that decision is selected for implemen-

tation, whether or not I opt out, I will still receive $£ 10$. Indeed, the decision to opt out from a donation is not very meaningful if no donation was made in the first instance. For this reason, from now on we restrict attention to those for whom the decision to opt out has implications in terms of personal pay off, i.e. those who passed something in the decision selected for implementation. This 
leaves us with a sample of 109 participants $;^{7}$ in this sample more than one third of the subjects (37 out of 109) decided to opt out.

If we look at the decision to opt out by treatment (see the left-hand side of Table 1) what we see is that people are more likely to opt out when T1 is implemented, namely, when the experimenters are the recipients. In this case, more than half of those who had decided to give something, when given the opportunity withdraw their donation and keep $£ 10$ instead. On the other hand, when a charity is involved, only around a quarter of those who had decided to give something opt out (21\% for T2, 29\% for T3). The difference between the two treatments involving charities (T2 and T3) is not statistically significant, while the differences between the treatment involving the experimenters and the treatments involving charities are. The fact that subjects are more likely to opt-out when the recipient is the experimenters is probably related to the fact that the moral cost associated with opting out is lower in this case compared to the case when the recipient is a charity.

Allowing participants to opt out had important quantitative implications in our experiment. In particular, participants in the sample we use for the analysis would have donated a total of $£ 511$ (an average of $£ 4.7$ each) if the experiment had stopped after the three sequential decisions, while they actually donated a total of $£ 350$ ( 33.2 each on average). Thus, giving the opportunity to opt out reduced donations by one third. Donations to experimenters are particularly affected, dropping by half from $£ 124$ to $£ 58$, but also donations that participants made to charities dropped by a remarkable $25 \%$, from $£ 388$ to $£ 292$.

Looking at the decision to opt out by position (see the right-hand side of Table 1), we do not find a particular trend, with $34 \%$ of subjects opting out when their first decision is implemented, while the figures for the second and third decision are $40 \%$ and $28 \%$ respectively, with these differences not being statistically significant. ${ }^{8}$

As the left hand side of Table 2 shows, the "stakes" at hand were not different between those opting out and whose standing behind their initial decision. For instance, when T3 was the decision implemented, those opting out had given on average $£ 4.86$, while those not opting out had given on average £5.28. Both t-tests and tests on the equality of distributions, such as, the WilcoxonMann-Whitney test and the Kolmogorov-Smirnov test, fail to reject the null that mean giving, or the distribution of giving, was the same between the two groups across the different treatments. One could have expected that those that opted out did so because they had given much more in the

\footnotetext{
${ }^{7}$ Thus, $43 \%$ of our original sample gives nothing in the decision that is selected for implementation.

${ }^{8}$ We cannot reject the null that the implemented treatment and the implemented position within the sequence are independent ( $\mathrm{p}$-values for Pearson chi2 test=0.979, for likelihood-ratio chi2 test=0.978, for Fisher's exact test=0.977). The same is true if we only consider implemented treatment and implemented position for those for whom the decision to opt out has implications in terms of personal pay off ( $\mathrm{p}$-values for Pearson chi2 test $=0.748$, for likelihood-ratio chi2 test $=0.746$, for Fisher's exact test $=0.764$ ). Thus, randomization was successful and it makes sense to look at the decision to opt out by treatment and by position separately.
} 
decision selected for implementation and so had more to gain from the decision to opt out of their previous allocation decision and receive $£ 10$ instead. On the other hand, the fact that somebody has given a lot means that he or she cared about donations, thus, making opting out less likely. As it turned out, these two contrasting forces cancel out and those opting out are as generous as those not opting out, when generosity is measured by their allocation decisions before opting out. The right-hand side of Table 2, reports giving in all three treatments separately for those that opted out and those that did not. From this table it is evident, for instance, that regardless of the decision that was randomly selected for implementation, those opting out gave on average $£ 5.04$ to a charity in T3, while those not opting out gave $£ 5.47$, and, once again, we fail to reject the null that mean giving, or the distribution of giving, was the same between the two groups.

These results are confirmed by a regression analysis (see Table 3), showing that the probability of opting out is unrelated to the position in which the implemented decision is taken, while opting out is more likely if the implemented decision concerns the donation to the experimenters (T1) instead of donation to a charity (T2 and T3). This is the case even when we control for the amount that the subject originally donated in the implemented decision, a variable that, consistently with the left-hand side of Table 2, is unrelated to the probability of opting out.

As mentioned earlier, we invited an equal number of males and females in each session, with the purpose of testing for possible gender effects. Out of the 109 participants for whom the decision to opt out has implications in terms of personal pay off, 59 are males and 50 are females. Among the 37 who decided to opt out, 18 are males (31\% of all males) and 19 are females (38\% of all females). We fail to reject the null hypothesis that the decision of opting out and gender are unrelated. ${ }^{9}$

\section{Discussion}

Why is it the case that a sizeable share of subjects in our experiment decided to give something either to a charity or to the experimenters, but then withdrew their donation and kept everything for themselves? One possible explanation, given that in our design decisions are taken sequentially, would be that participants acquire additional information as the experiment goes on and this induces them to reconsider their choice at the opt out stage. For instance, subjects may give generously to the experimenters when this is the first decision they face. However, later on, once they see treatments involving charities, they may reconsider the "worthiness" of the experimenters and regret their initial donation. Considering that in our design there is random implementation of one of the three decisions, giving in any one treatment does not affect in any way the material payoffs associated with the other treatments. Still, learning about the experiment may induce some

\footnotetext{
${ }^{9} \mathrm{P}$-values for Pearson chi2 test $=0.410$, for likelihood-ratio chi2 test $=0.411$, for Fisher's exact test $=0.425$. Also, the coefficient of a gender dummy added to the regressions in Table 3 is always insignificant (results not reported).
} 
people to reconsider their initial decisions. If this were the case, then we would expect a strong trend in opting out, with a high incidence for decisions taken early on, and basically no incidence at all for the decision taken just before the opt out option was presented, as no additional information about the experiment could be acquired in this stage. As outlined above, no trend emerges from the data, with opting out having a strong incidence also for the third decision in the sequence. We can thus exclude the possibility that the acquisition of information about the experiment is what is driving our results.

Our claim is that this pattern of revision of the decision to give in the first three rounds of the experiment suggests that giving in the first instance was not motivated exclusively by a desire to improve the payoff of the recipient, but was also driven by the decision-maker's desire to selfsignal her altruistic inclination. The reversal being attributed to self-signaling is consistent with the theoretical framework of Bodner and Prelec (2003) who develop a model of choice in which the decision maker has a utility function with two components: outcome value, which is the benefit derived from helping the charitable cause per se and diagnostic value, which is the value derived from becoming informed about one's level of altruism from the action taken. ${ }^{10}$ In this framework, Bodner and Prelec suggest that "A self-signaling person will be more likely to reveal discrepancies between resolutions and actions, when resolutions pertain to actions that are contingent or delayed. Thus she might honestly commit to do some worthy action if the circumstances requiring the action were remote (temporally or probabilistically), but would in fact regret the commitment if those circumstances were obtained." (Bodner and Prelec, 2003, page 107). In our experiment, the payoff consequence of the three sharing decisions that subjects make is both uncertain (each will be implemented with equal probability of one-third) and will be revealed with delay at the end of the experiment. If this aspect leads subjects to discount the utility they obtain from payoffs when they make the sharing decisions and not when they decide to exit, while the self-signaling component of utility remains the same, then this would explain the reversal of choices we observe.

Moreover, satiation of utility benefits deriving from self-signaling may also account for the opting out we observe. To see the logic behind the argument more clearly note that the decision to opt-out may not fully erase the benefits to a person's self-esteem deriving from the previous decisions that were not implemented, perhaps, not even from the one that was actually implemented and from which the subject walked away. If that is true, then the decision maker can leverage the benefits to self-esteem deriving from decisions that were not implemented and this may lead her to withdraw an amount that was initially chosen to be shared.

\footnotetext{
${ }^{10}$ The experiments reported in Bodner (1995) provide evidence of charitable giving driven by the diagnostic value it furnishes regarding the individual's altruistic disposition.
} 


\section{References}

[1] Andreoni, J. (1989): "Giving with Impure Altruism: Applications to Charity and Ricardian Equivalence," Journal of Political Economy, 97(6), 1447-58.

[2] Andreoni, J. (1990): "Impure Altruism and Donations to Public Goods: A Theory of WarmGlow Giving," Economic Journal, 100(401), 464-477.

[3] Andreoni, J., and Bernheim, B.D. (2009): "Social Image and the 50-50 Norm: A Theoretical and Experimental Analysis of Audience Effects," Econometrica, 77(5), 1607-1636.

[4] Ariely, D., Bracha, A., and Meier, S. (2009): "Doing Good or Doing Well? Image Motivation and Monetary Incentives in Behaving Prosocially," American Economic Review, 99(1), 544-55.

[5] Baumeister, R. F. (1998): "The Self," in The Handbook of Social Psychology, ed. by D. T. Gilbert, S. T. Fiske, and G. Lindzey, pp. 680-740. New York: McGraw-Hill.

[6] Bem, D. J. (1972): "Self-perception Theory," in Advances in Experimental Social Psychology, ed. by L. Berkowitz, vol. 6, pp. 1-62, New York: Academic Press.

[7] Benabou, R., and Tirole, J. (2006): "Incentives and Prosocial Behaviour," American Economic Review, 96(5), 1652-1678.

[8] Bodner, R., (1995): Self Knowledge and the Diagnostic Value of Actions: The Case of Donating to a Charitable Cause, Unpublished Doctoral Dissertation, MIT, Sloan School of Management.

[9] Bodner, R., and Prelec, D. (2003): "Self-signaling and Diagnostic Utility in Everyday Decision Making," in The Psychology of Economic Decisions, vol. Rationality and Well- being, ed. by I. Brocas, and J. Carillo, chap. 6, Oxford University Press.

[10] Broberg, T., Ellingsen, T., and Johannesson, M. (2007): "Is Generosity Involuntary," Economics Letters, 94(1), 32-37.

[11] Dana, J., Cain, D.M., and Dawes, R. (2006): "What you don't know won't hurt me: Costly (but quiet) exit in a dictator game," Organizational Behavior and Human Decision Processes, 100(2), 193-201.

[12] DellaVigna, S., List, J., and Malmendier, U. (2011): "Testing for Altruism and Social Pressure in Charitable Giving," Quarterly Journal of Economics, forthcoming.

[13] Ellingsen, T., and Johannesson, M. (2008): "Pride and Prejudice: The Human Side of Incentive Theory," American Economic Review, 98(3), 990-1008. 
[14] Ellingsen, T., and Johannesson, M. (2011): "Conspicuous Generosity," Journal of Public Economics, 95(9-10), 1131-1143.

[15] Ellingsen, T., Johannesson, M., Tjotta, S., and Torsvik, G., (2010): "Testing Guilt Aversion," Games and Economic Behavior, 68(1), 95-107.

[16] Fehr, E., and Schmidt, K.M. (1999): "A Theory of Fairness, Competition and Cooperation," Quarterly Journal of Economics, 114, 817-868.

[17] Grossman, Z. (2010): "Self-Signaling versus Social Signaling in Giving," UCSB Working paper.

[18] Jacobsen, K.J., Eika, K.H., Helland, L., Lind, J.T., Nyborg, K. (2011): "Are Nurses More Altruistic than Real Estate Brokers?" Journal of Economic Psychology, 32(5), 818-31.

[19] Lacetera, N., and Macis, M., (2010): "Social Image Concerns and Prosocial Behavior: Field Evidence from a Nonlinear Incentive Scheme," Journal of Economic Behavior and Organization, $76(2), 225-237$.

[20] Lazear, E.P., Malmendier, U., and Weber, R.A. (2012): "Sorting in Experiments with Application to Social Preferences," American Economic Journal: Applied Economics, 4(1), 136-63.

[21] Murnighan, J.K., Oesch, J.M., and Pillutla, M. (2001): "Player Types and Self-Impression Management in Dictator Games: Two Experiments," Games and Economic Behavior, 37, 388414.

[22] Tonin, M. and Vlassopoulos, M. (2011): "An Experimental Investigation of Intrinsic Motivations for Giving," IZA Discussion Paper No. 5461. 
Table 1: Proportion Opting Out

\begin{tabular}{|c|c|c|c|c|c|c|}
\hline \multirow[b]{2}{*}{ Opt Out } & \multicolumn{3}{|c|}{ by Treatment } & \multicolumn{3}{|c|}{ by Position } \\
\hline & $\mathrm{T} 1$ & $\mathrm{~T} 2$ & T3 & DA & DB & DC \\
\hline NO & 15 & 23 & 34 & 33 & 18 & 21 \\
\hline YES & 17 & 6 & 14 & 17 & 12 & 8 \\
\hline$\%$ YES & $53 \%$ & $21 \%$ & $29 \%$ & $34 \%$ & $40 \%$ & $28 \%$ \\
\hline \multicolumn{2}{|c|}{ Tests (p-values) } & Pearson $\chi 2$ & Fisher's exact & & Pearson $\chi 2$ & Fisher's exact \\
\hline \multicolumn{2}{|l|}{ All } & 0.02 & 0.02 & & 0.60 & 0.64 \\
\hline \multirow[t]{3}{*}{ Pairwise: } & T1 vs T2 & 0.01 & 0.02 & DA vs DB & 0.59 & 0.64 \\
\hline & T1 vs T3 & 0.03 & 0.04 & DA vs DC & 0.56 & 0.62 \\
\hline & T2 vs T3 & 0.41 & 0.59 & DB vs DC & 0.31 & 0.41 \\
\hline
\end{tabular}

$D A, D B$, and $D C$ stands for first, second and third decision in the sequence.

$\mathrm{T} 1, \mathrm{~T} 2, \mathrm{~T} 3$ stands for treatment 1,2 , and 3, respectively. 
Table 2: Comparison of Giving

\begin{tabular}{|c|c|c|c|c|c|c|c|}
\hline \multirow{2}{*}{\multicolumn{2}{|c|}{ Opt Out }} & \multicolumn{3}{|c|}{ Implemented Treatment } & \multicolumn{3}{|c|}{ Any Treatment } \\
\hline & & T1 & $\mathrm{T} 2$ & T3 & T1 & T2 & T3 \\
\hline \multirow[t]{3}{*}{ NO } & Mean & 3.85 & 4.89 & 5.28 & 2.77 & 3.01 & 5.47 \\
\hline & SD & 2.53 & 2.71 & 3.18 & 2.64 & 2.91 & 3.05 \\
\hline & $\mathrm{N}$ & 15 & 23 & 34 & & 72 & \\
\hline \multirow[t]{3}{*}{ YES } & Mean & 3.89 & 4.58 & 4.86 & 2.53 & 2.69 & 5.04 \\
\hline & SD & 1.89 & 1.96 & 2.74 & 2.55 & 3.00 & 3.04 \\
\hline & $\mathrm{N}$ & 17 & 6 & 14 & & 37 & \\
\hline \multicolumn{2}{|c|}{ T-test } & 0.96 & 0.80 & 0.66 & 0.65 & 0.59 & 0.48 \\
\hline \multicolumn{2}{|c|}{ WMW } & 0.80 & 0.74 & 0.70 & 0.56 & 0.42 & 0.49 \\
\hline \multicolumn{2}{|l|}{ KS } & 0.81 & 0.93 & 0.52 & 0.96 & 0.87 & 0.92 \\
\hline
\end{tabular}

WMW: Wilcoxon-Mann-Whitney test. KS: Kolmogorov-Smirnov test. P-values are indicated for tests.

$D A, D B$, and $D C$ stands for first, second and third decision in the sequence.

$\mathrm{T} 1, \mathrm{~T} 2, \mathrm{~T} 3$ stands for treatment 1,2 , and 3, respectively. 
Table 3: Regression Analysis

\begin{tabular}{|c|c|c|c|c|c|c|}
\hline \multicolumn{7}{|c|}{ Dependent Variable: Opt out (1: YES, 0: No) } \\
\hline Model & Linear & Probit & Logit & Linear & Probit & Logit \\
\hline Constant & $0.54 * * *$ & 0.10 & 0.16 & $0.59 * * *$ & 0.28 & 0.45 \\
\hline s.e. & 0.10 & 0.26 & 0.42 & 0.12 & 0.35 & 0.57 \\
\hline DC & 0.06 & 0.17 & 0.28 & 0.06 & 0.16 & 0.27 \\
\hline s.e. & 0.11 & 0.31 & 0.50 & 0.11 & 0.31 & 0.50 \\
\hline DB & -0.08 & -0.21 & -0.38 & -0.10 & -0.29 & -0.50 \\
\hline s.e. & 0.11 & 0.32 & 0.53 & 0.11 & 0.33 & 0.56 \\
\hline $\mathrm{T} 2$ & $-0.33 * * *$ & $-0.90 * * *$ & $-1.51 * * *$ & $-0.32 * * *$ & $-0.88 * *$ & $-1.47 * *$ \\
\hline s.e. & 0.12 & 0.34 & 0.59 & 0.12 & 0.35 & 0.59 \\
\hline T3 & $-0.24 * *$ & $-0.64 * *$ & $-1.04 * *$ & $-0.23 *$ & $-0.60 * *$ & $-0.97 * *$ \\
\hline s.e. & 0.11 & 0.30 & 0.48 & 0.11 & 0.30 & 0.49 \\
\hline Pass & & & & -0.01 & -0.04 & -0.06 \\
\hline s.e. & & & & 0.02 & 0.05 & 0.09 \\
\hline (Pseudo) R2 & 0.08 & 0.07 & 0.07 & 0.09 & 0.07 & 0.07 \\
\hline Log-Likelihood & & -65.27 & -65.21 & & -64.97 & -64.93 \\
\hline
\end{tabular}

Sample size: 109. Robust S.E. for the linear model.

Pass: amount that the subject originally donated in the implemented decision.

DB, and DC stands for second and third decision in the sequence. T2, T3 stands for treatment 2 and 3.

DA and T1 are the omitted categories.

$*(* *)[* * *]$ indicates significant at the $10 \%(5 \%)[1 \%]$ level. 